\title{
Measurement and the Stochastic Analyses of Particle Distribution Pattern on Sea Surface*1
}

\author{
Kei TAKIZAWA*2 and Wataru SAKAMOTO*2 \\ (Received September 18, 1979)
}

\begin{abstract}
To study the characteristics of particle distribution in waters the authors developed new apparatus applying the principle of light beam interruption. Two experimental series were carried out in different places, one was a small scale measurement at the inner part of bay and the other was open sea.

As the variation of "particle numbers in every unit tow length (PARTICLE NUMBER)" was regarded as a stochastic process, power spectrum of PARTICLE NUMBER, histogram and $I_{\delta}$ index were calculated in each case. They suggested that distribution patterns near sea surface could be classified into two groups, daytime pattern and night one. In the former case histograms of PARTICLE NUMBER seemed to be Poisson (random distribution) and in the latter Polya-Eggenberg's distribution (contagious distribution). The fluctuation of PARTICLE NUMBER in some neighboring quadrats was examined and it was detected that the conditional probability of the process decreased exponentially. It was inferred that the relation between transition probability and state space in Markov Process is applicable to the fluctuation of PARTICLE NUMBER.
\end{abstract}

The formation of patchiness of living organic matter and their dispersion process are mostly dependent on the differential kinetic properties of ocean flow, divergence, volticity, shearing deformation rate and streching deformation rate ${ }^{11}$. For instance, the deformations are important in the evolution of oceanic frontal zone, such as "Shiome." Several trials to calculate numerical values of them horizontally have been done by the method of curfol tracking ${ }^{2,3)}$. Measurement of the density and distribution scale of zoo-plankton patchiness is possible since equipment has been developed to collect samples at intervals of a few meters $^{4,5}$. Furthermore spectral analyses of phytoplankton variances both time and spatial series data are reported by the fluorescence of chlorophyll pigments $^{6,71}$. In the series of these reports PLATT ${ }^{81}$ (1972) discussed the similarity of water diffusion and concluded that over length scales between $10 \mathrm{~m}$ and $1 \mathrm{~km}$ the local abundance of phytoplankton might be controled by the physical transportation process of the water and not any dynamic behavior of the organism. But there are many difficulties to correlate the physical process with biological characteristics of patchiness. For the purpose to research directly the patchiness or other distribution patterns of parti- culate matter on sea surface, in situ, the authors are developing continuous counting apparatus. This is our first test of the operation at open sea.

\section{Apparatus and Method}

The apparatus which was attached to the end of plankton net instead of backet, consists of the acrylic resinous pipe of $59 \mathrm{~mm}$ diameter and 100 mm length. The $1 \mathrm{~mm}$ width parallel light beam is sent from a side of the pipe, and the opposite side Cd-S photoresistor is attached, which has 15 milisecond time constant, to receive the fluctuation of light intensity that occurs when particles interrupt the beam. Both light source and photoresistor were set in the small water tight chamber. The electric stabilizer is put between light beam and source to avoid the effect of electric power fluctuation (Fig. 1). The electric power was supplied from dry batteries through the cable and signal of photoresistor was converted to electric potential by bridge circuit, which was arranged and operated on board.

To know the difference of distribution both in time and space, two experimental series have been tried; one was in the Maizuru Bay (named U), where it was possible to obtain the small scale

*1 This work was orally presented to the Annual Meeting of Japan. Soc. Sci. Fish. at Shimizu in October, 1978.

*2 Department of Fisheries, Faculty of Agriculture, Kyoto University, Sakyo-ku, Kyoto 606, Japan (滝沢 教・板本 亘: 京都大学费学部). 


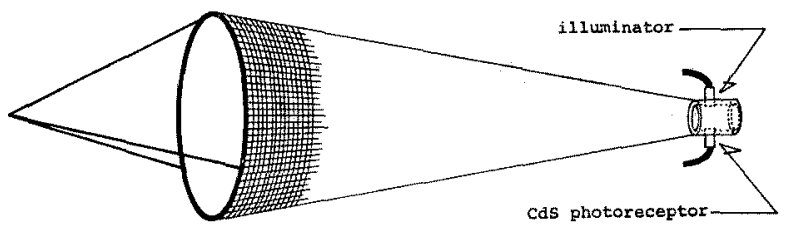

Fig, 1. Schema of apparatus. Net is NORPAC type.

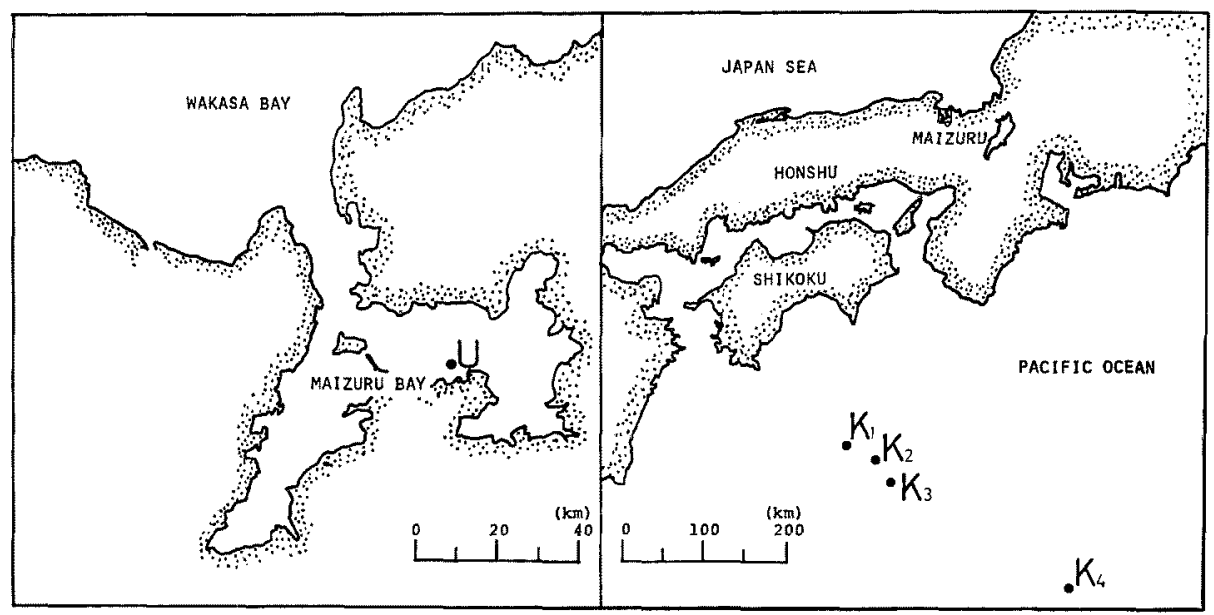

Fig. 2. Experimental location. left: $U$ in Maizuru Bay, right: $K_{1}-K_{4}$ around and inner part of "Kuroshio".

distribution within $10 \mathrm{~m}$ to $1 \mathrm{~km}$, the other were carried out during 10 to 12-th on August, 1977, within the area of $31^{\circ} 53^{\prime} 07^{\prime \prime} \mathrm{N}, 134^{\circ} 06^{\prime} 00^{\prime \prime} \mathrm{E}$ and $30^{\circ} 16^{\prime} 09^{\prime \prime} \mathrm{N}, 134^{\circ} 03^{\prime} 01^{\prime \prime} \mathrm{E}$ on the cruise of $\mathrm{KH}-$ 77-2, R. V. Hakuho-maru, of Ocean Research Institute, University of Tokyo. The counting time were staggered from midnight to daytime to know the differences of diurnal distribution patterns (named $K_{1}, K_{2}, K_{3}, K_{4}$ respectively). The summary is shown in Table 1. Within this area the vessel was drifting almost all the time except during the plankton haul and drougue tracking, so we can presume the vessel was moving with the same water through the experiment.

The apparatus was set at few meters depth and was towed at 2 knots from the starboard of the vessel. As the light beam interruption was indicated by pulse arrangement, we counted these pulse in every unit length on the analog record and defined "particle numbers in every unit tow length (PARTICLE NUMBER)". The unit tow length were estimated by the ship speed and considered about 5 meters on $U$ series and 30 meters at open sea.

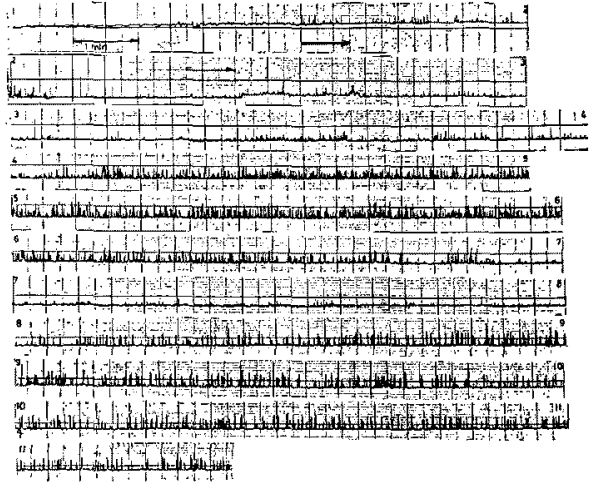

Fig. 3. An example of data observed in run $K_{4}$ Data goes from left to right and down in turn.

\section{Results and Discussion}

The example of original data is presented in Fig. 3. The records were inspected and the fluctuation of PARTICLE NUMBER $N(x)$ are presented in Fig. 4. In every series linear trends or some periodicities may be detected. The statistical 
Table 1. Summary of experimental position and date

\begin{tabular}{|c|c|c|c|c|}
\hline Run & Start & End & Date & Time \\
\hline $\mathbf{U}$ & $\begin{array}{r}35^{\circ} 29^{\prime} \mathrm{N} \\
135^{\circ} 22^{\prime} \mathrm{E}\end{array}$ & - & 1976.11 .28 & $19: 45-20: 23$ \\
\hline $\mathbf{K}_{1}$ & $\begin{array}{r}31^{\circ} 54^{\prime} \mathrm{N} \\
134^{\circ} 06^{\prime} \mathrm{E}\end{array}$ & $\begin{array}{r}31^{\circ} 55^{\prime} \mathrm{N} \\
134^{\circ} 09^{\prime} \mathrm{E}\end{array}$ & 1977.8 .10 & $00: 00-02: 00$ \\
\hline $\mathbf{K}_{\mathbf{2}}$ & $\begin{array}{r}31^{\circ} 45^{\prime} \mathrm{N} \\
134^{\circ} 28^{\prime} \mathrm{E}\end{array}$ & - & 8.10 & $14: 00-14: 35$ \\
\hline $\mathbf{K}_{3}$ & $\begin{array}{r}31^{\circ} 45^{\prime} \mathrm{N} \\
134^{\circ} 41^{\prime} \mathrm{E}\end{array}$ & - & 8.10 & $22: 00-22: 35$ \\
\hline $\mathbf{K}_{4}$ & $\begin{array}{r}30^{\circ} 18^{\prime} \mathrm{N} \\
136^{\circ} 40^{\prime} \mathrm{E}\end{array}$ & $\begin{array}{r}30^{\circ} 16^{\prime} \mathrm{N} \\
137^{\circ} 03^{\prime} \mathrm{E}\end{array}$ & 8.12 & $16: 00-21: 00$ \\
\hline
\end{tabular}
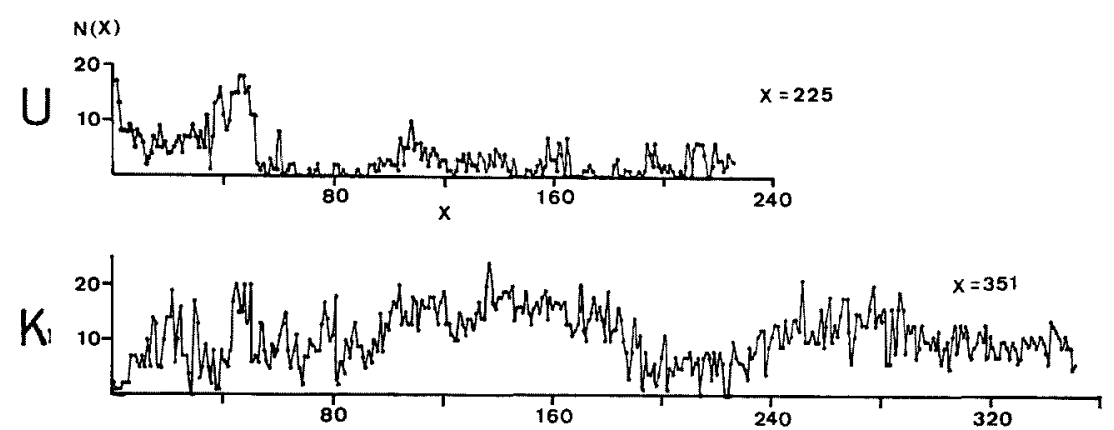

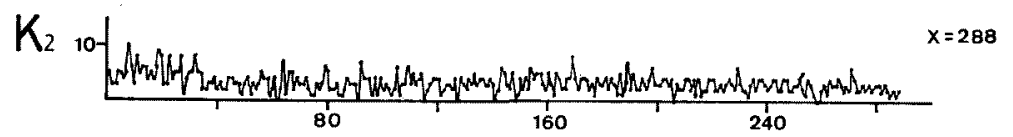

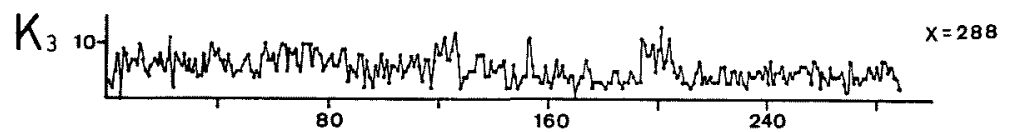
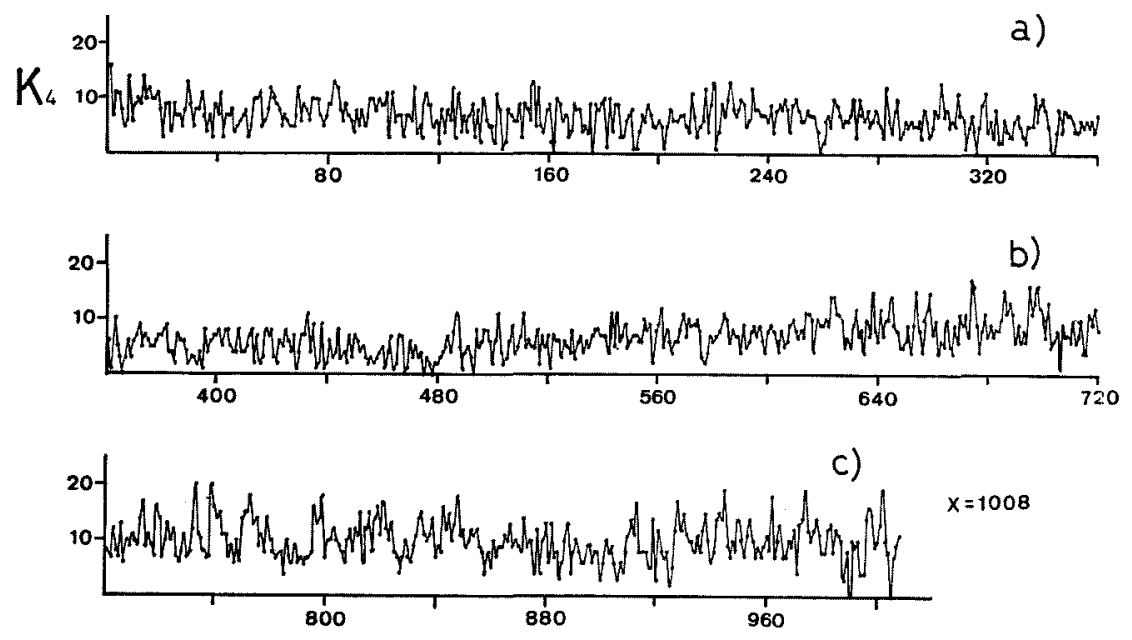

Fig. 4. Seriation of "particle numbers observed in every unit tow length (PARTICLE NUMBER)" The unit tow length are about 5 meters in $\mathbf{U}$ and 30 meters in $\mathbf{K}_{\mathbf{1}}-\mathbf{K}_{\mathbf{4}}$. 


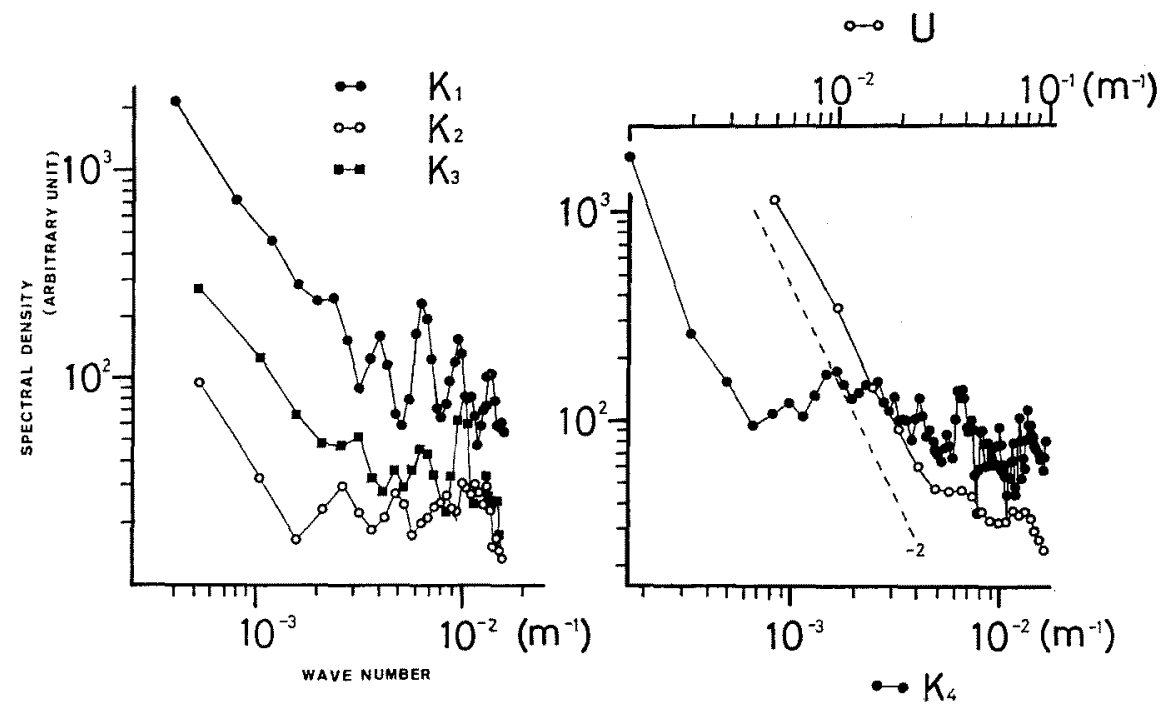

Fig. 5. Power spectra of PARTICLE NUMBER $N(x)$.

analyses ( $t$-test) had been attempted to determine whether linear trends larger than the observation scale existed and it was ascertained there was no trend in any series.

According to the results of spectral analyses of $N(x)$ (Fig. 5), the slope of power row was about -2 within the range of small wave number, which means the distribution somehow depend upon the Poisson process ${ }^{91}$. These phenomena are clearly shown in $U$ series and in the range of less than $1.7 \times 10^{-3}\left(m^{-1}\right)$ of other series of $\mathrm{K}_{1}, \mathrm{~K}_{2}, \mathrm{~K}_{\mathbf{3}}$.

There are some changes in appearance of characteristic periodicity. That is, two peaks in $6.7 \times$ $10^{-3}$ and $1.0 \times 10^{-2}\left(\mathrm{~m}^{-1}\right)$ were observed in $\mathrm{K}_{1}$ and $K_{3}$ series which were carried out during night and midnight, but in the series of $\mathrm{K}_{2}$ measured in daytime they disappeared. The distribution patterns might be influenced by two types of fluctuation, one was invariable through the day and night, another was variable between day and night that was brought by the vertical migration of living organism. This view is supported by counting mean numbers in every PARTICLE NUMBER series. They are as follows; $K_{1}$ is $11 / 30 \mathrm{~m}, K_{2}$ is $6 / 30 \mathrm{~m}$ and $K_{3}$ is $12 / 30 \mathrm{~m}$. The ratio of mean number in daytime to night is about $1: 2$.

Although spectral analyses correlate some periodicities with their amplitudes of $N(x)$ fluctuation, it is necessary to estimate the variance of $N(x)$. And we considered the probability distribution function (P. D. F.) of $N(x)$. The histogram of
PARTICLE NUMBER in each process and fitted theoretical distribution are shown in Fig. 6. These may be classified into two types; two series of $K_{2}$ and $K_{3}$ are Poisson type and others such as $\mathrm{U}, \mathrm{K}_{1}$ and $\mathrm{K}_{\mathbf{4}}$ are Polya-Eggenberg's distribution. The former is shown as

$$
P\left(r \mid \mu_{0}\right)=\mu_{0}^{r} \exp \left(-\mu_{0}\right) / r !
$$

where $\boldsymbol{P}\left(r \mid \mu_{0}\right)$ is P.D.F. of PARTICLE NUMBER $N(x), \mu_{0}$ is the average and $r$ is PARTICLE NUMBER. This distribution means those process were almost random. The Polya-Eggenberg's distribution, on the other hand, will be considered as follows. Though PARTICLE NUMBER $r$ is a function of the average $\mu$ and has Poisson distribution as shown in Eq. (1), the average $\mu$ is not constant through the process but variable between quadrats and follows in Gamma distribution function, that is,

$$
f(\mu)=(\mu / a)^{p-1} \exp (\mu / a) / a \cdot \Gamma(p)
$$

Then P.D.F. of latter case becomes

$$
P(r)=\frac{(r+p-1) ! a^{r}}{r !(p-1) !(a+1)^{p+r}}
$$

It shows the existence of patchiness because particle distribution was not mechanically uniform but has two characteristic parts, one was in high concentration area forming patchiness and the other was in low concentration area. These patchiness may be distributed randomly.

To make these phenomena clearer and to esti- 


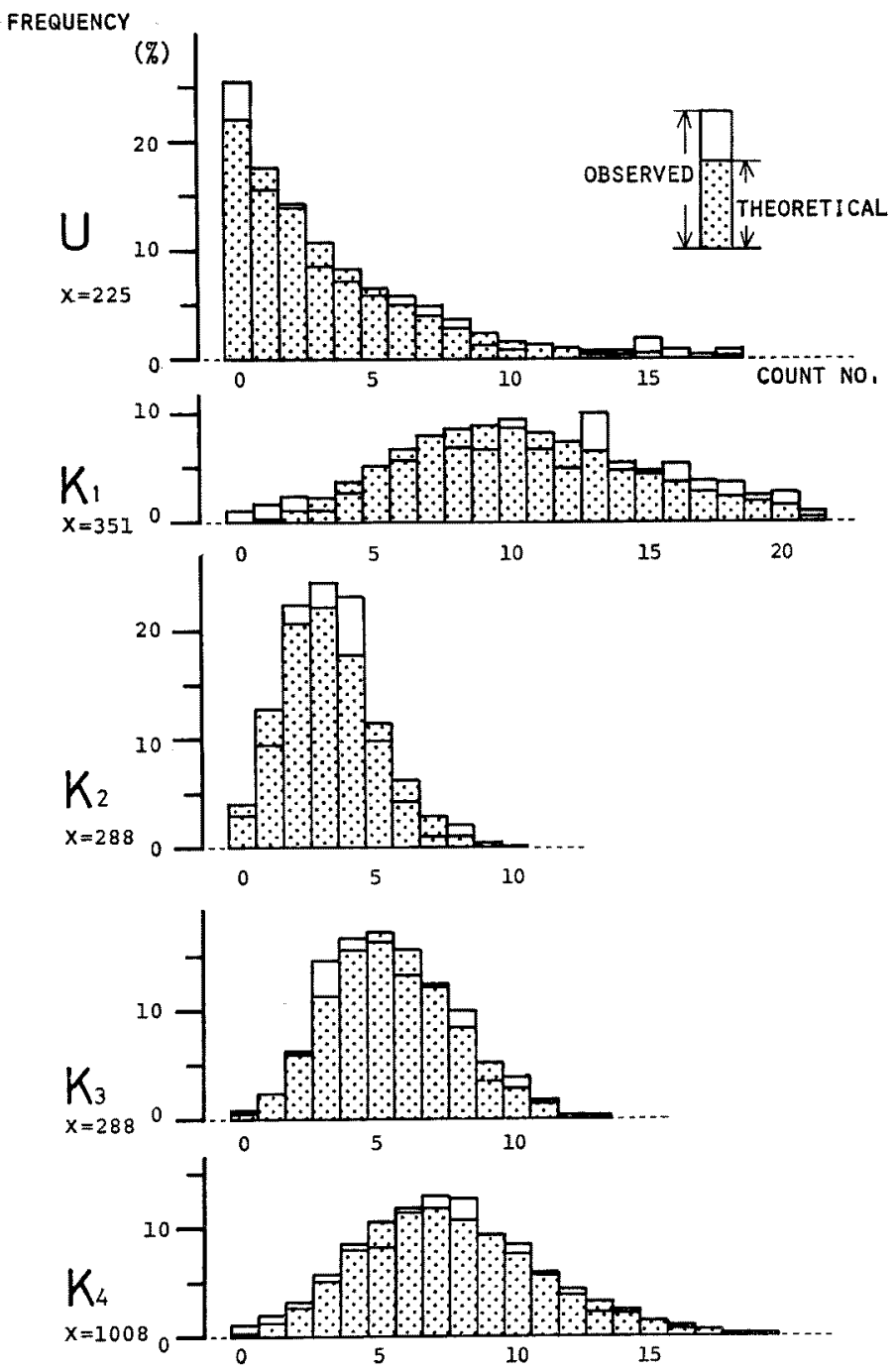

Fig. 6. Frequency distribution of PARTICLE NUMBER and fitted theoretical distribution.

mate the variance of $N(x)$ quantitatively we calculated $I_{\delta}$ index ${ }^{10)}$. Here the unit tow length was taken as unit quadrat size. After Morishita (1959) the distribution patterns were classified into three types; 1$) U$ : contagious, with small size patchiness though the separation distances among them are random. 2) $K_{1}$ and $K_{4}$ : contagious with large size patchiness. 3) $\mathrm{K}_{2}$ and $\mathrm{K}_{3}$ : completely random distribution. This classification was consistent with the characterization of histograms well. Two characteristic periodicities detected by spectral analyses were neglected by these analyses and it may be concluded that spectral analyses are very sensitive to the disposition order of PARTICLE NUMBER but histogram characterization or $I_{\delta}$ index indication is not so.

The actual distribution or motion of suspended particles in the sea is infuenced by the complex mechanism, for instance, the advection of surrounding waters or deterministic and random forces of organism, so it is almost impossible to track the trajectory of each individual by our method. Then we observed the numerical variation at a fixed area of $N(x)$. Those information may enable us to consider the characteristics of movement indirectly. So we regard the particle 


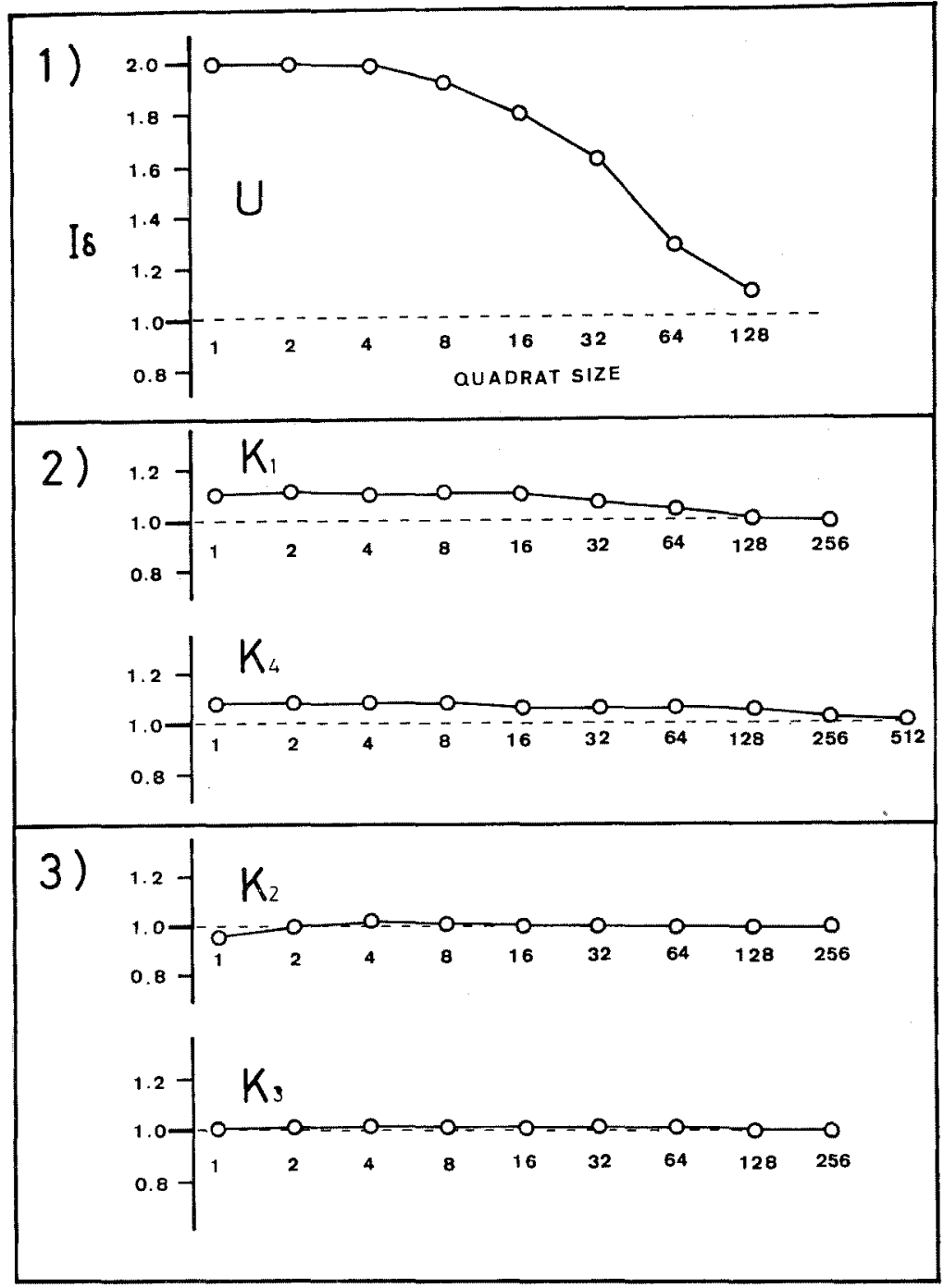

Fig. 7. Relation between count quadrat size (unit tow length) and $I_{\delta}$ index from Morishita (1959). 1): "Contagious with small clump but separation distance among them are random". 2): "Contagious with large clump but separation distance among them are random". 3): "Random distribution".

distribution pattern as a random phenomena and consider the conditional probability of a stochastic system $^{11}$.

Based on the histograms of PARTICLE NUMBER we can define stochastic permutation $p\left(x_{i}\right.$, $\left.N_{j}\right)$ instead of $N\left(x_{i}\right)$. The value of $p\left(x_{i}, N_{j}\right)$ indicates the series of probability element in the case when PARTICLE NUMBER in $i$-th quadrat is $N_{j}$ and constitutes the histogram of PARTICLE NUMBER $P d\left(N_{j}\right)$. Considering these stochastic permutations for $T$ seriate quadrats in all, the characteristics of fluctuation pattern in neighboring quadrats will be examined. If PARTICLE NUMBER in two neighboring quadrats changed as follows, i. e. in the former is $N_{j}$, and in the latter $N_{k}$, the conditional probability in the coupled quadrats $\rho_{1}\left(x_{i}, x_{i+1}\right)$ is

$$
\begin{gathered}
\rho_{1}=p\left(x_{i}, N_{j}\right) \cdot p\left(x_{i+1}, N_{k}\right)=P d\left(N_{j}\right) \cdot P d\left(N_{k}\right) \\
(i=1,2, \ldots, T-1)
\end{gathered}
$$




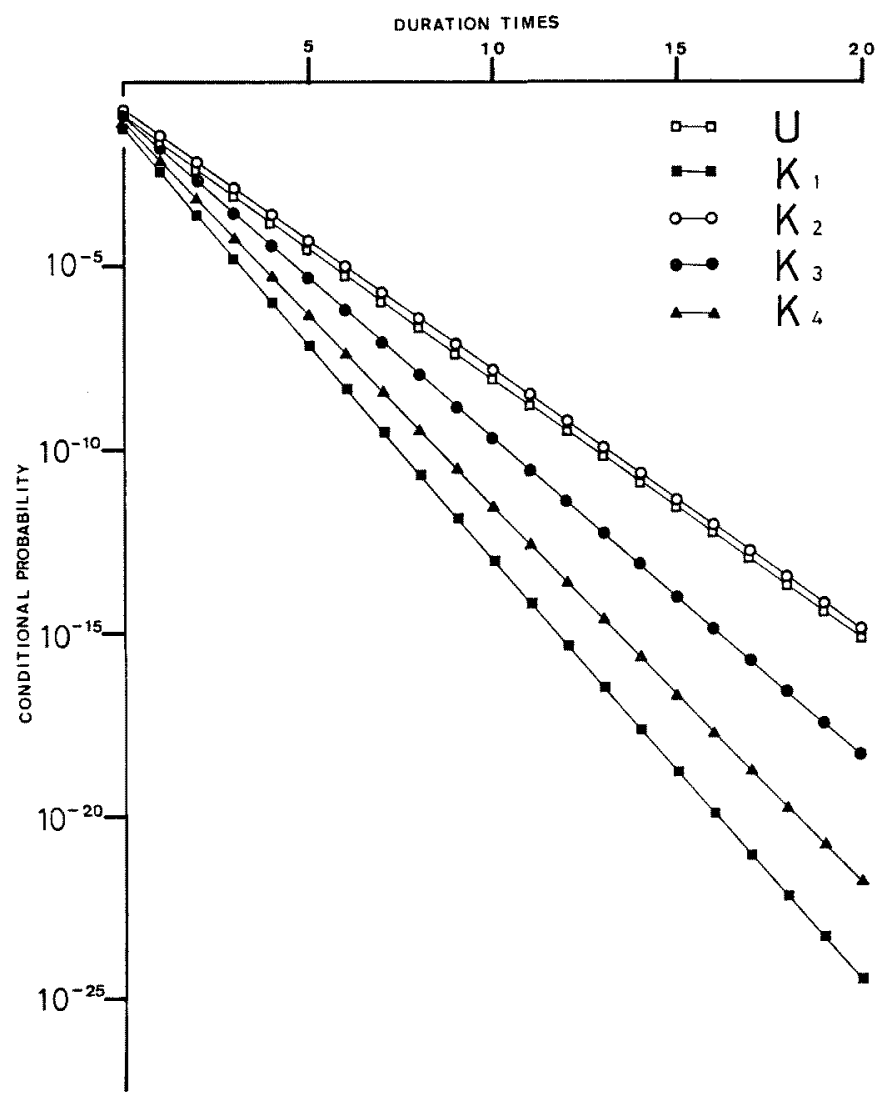

Fig. 8. Conditional probability $F(s)$ in a series of $s$ quadrats.

Then we have $(T-1) \rho_{1}\left(x_{i}, x_{i+1}\right)$ and define $F(1)$ which means the average of $\rho_{1}\left(x_{i}, x_{i+1}\right)$ through this process. Namely,

$$
\begin{aligned}
F(1) & =\bar{\rho}_{1}=\frac{1}{T-1} \sum_{j=1}^{T-1} \rho_{1}\left(x_{i}, x_{i+1}\right) \\
& =\frac{1}{T-1} \sum p\left(x_{i}, N_{j}\right) \cdot p\left(x_{i+1}, N_{k}\right)
\end{aligned}
$$

And $F(2), F(3), \ldots, F(s)(s<T)$ becomes as follows,

$$
\begin{aligned}
& F(2)=\bar{\rho}_{\mathbf{2}}=\frac{1}{T-2} \sum_{i=1}^{T-2} p\left(x_{i}, N_{j}\right) \cdot p\left(x_{i+1}, N_{k}\right) \\
& \cdot p\left(x_{i+2}, N_{l}\right) \\
& F(s)=\bar{\rho}_{s}=\frac{1}{T-s} \sum_{i=1}^{T-s}\left\{\prod_{j=0}^{s} p\left(x_{i+j}, N_{k}\right)\right\}
\end{aligned}
$$

where $F(s)$ indicates mean conditional probability in a series of $s$ quadrats. As shown in Fig. 8, $F(s)$ seems to decrease semilogarithmically when $s$ increases, so $F(s)$ can be expressed just by $\rho_{0}$ and $s$.

$$
F(s)=\rho_{0} \cdot F(s-1)=\rho_{0}^{s} \quad\left(0<\rho_{0}<1\right)
$$

$\rho_{0}$ indicates the durability rate, and when $\rho_{0}$ is relatively large, $N(x)$ fluctuates smoothly such as $\mathrm{K}_{2}$ or $\mathrm{U}$, but when $\rho_{0}$ is small, $N(x)$ fluctuates irregularly.

From the results of them we infered that the relation between transition probability and state space in Markov Process is applied to the fluctuation of PARTICLE NUMBER. A transition probability is got from the two dimensional probability distribution of PARTICLE NUMBER alteration in neighboring two quadrats. It is very convenient for showing every PARTICLE NUMBER alteration of $N(x)$ to take a matrix $M$ which consists of $N_{i j}$ that indicates the frequency of number varing from $i$ to $j$ in neighboring two quadrats. And this matrix is the two dimensional probability distribution as mentioned previously. The row vector of $M$ indicates the causal 
Table 2. Matrix indicating change pattern of PARTICLE NUMBER in a coupled quadrat (RUN of $\mathrm{K}_{3}$ ). Itaric number shows the particles observed in the former quadrat (column) and in the latter (row) of a coupled quadrat through the process. $C_{i j}$ is correlation coefflcient of the row and column vector.

\begin{tabular}{|c|c|c|c|c|c|c|c|c|c|c|c|c|c|c|c|}
\hline & & \multicolumn{14}{|c|}{$C_{t j}=0.369$} \\
\hline & & \multicolumn{14}{|c|}{$j$} \\
\hline & & 0 & 1 & 2 & 3 & 4 & 5 & 6 & 7 & 8 & 9 & 10 & 11 & 12 & 13 \\
\hline \multirow{13}{*}{$i$} & $\begin{array}{l}0 \\
1\end{array}$ & & & & 1 & & & & 1 & & 1 & & & & \\
\hline & 2 & & & 1 & 5 & 2 & 3 & 2 & 2 & 1 & & & & & \\
\hline & 3 & & 1 & 6 & 12 & 7 & 7 & 5 & 3 & & & & 1 & & \\
\hline & 4 & 1 & & 3 & 8 & 13 & 7 & 6 & 5 & 4 & & & 1 & & \\
\hline & 5 & & & 1 & 5 & 11 & 9 & 7 & 6 & 5 & 2 & 1 & & & \\
\hline & 6 & & & 1 & 5 & 9 & 5 & 6 & 6 & 4 & 1 & 1 & & & \\
\hline & 7 & & & 2 & 4 & 3 & 8 & 4 & 6 & 3 & 2 & 2 & 2 & & \\
\hline & 8 & 1 & & 2 & & 3 & 6 & 4 & 2 & 5 & 2 & 3 & 1 & & \\
\hline & 9 & & & & 1 & & & 1 & 1 & 3 & 2 & & & 1 & 1 \\
\hline & 10 & & & & & & 2 & 1 & 2 & 3 & & 3 & & & \\
\hline & 11 & & & 1 & & & & 1 & 2 & & 3 & & & & \\
\hline & 12 & & & & & & & & & 1 & & & & & \\
\hline & 13 & & & & & & & 1 & & & & & & & \\
\hline
\end{tabular}

frequency (C. F.) and the column vector is the resultant frequency (R. F.). Any extreme change is hardly observed but there will be some resemblance between two seriate quadrats and this is also proved by the correlation coefficient $C_{i j}$ between C. F. and R. F. (Table 2), And deviding each element of row vector by the sum, the transition probability $\operatorname{Tr}$ is defined.

If we could have obtained the other informations about the kind or size of particles, we might add a few deterministic solution in the same way of our stochastical analyses. For example, the vertical distribution of some phytoplankton biomass may be discussed by solving the equation of motion which takes into account of turbulent diffusivity and sinking speed ${ }^{12,13)}$. But there is no information about these factors and it is difficult to describe the characters of the deterministic distribution pattern. However it would be necessary to consider Markov process in the distribution or motion of suspended particles in the sea and we are investigating the property of transition probability $T r$.

Electronic particle counting method is less effective for larger animals such as macrozooplankton or nekton because of their lower abundance and avoidance ability as pointed out by DENMAN and MACKAs $^{14}$ ? In our experiment the matter crossed the beam was unknown. They were organic or inorganic. It is necessary to use some sorts of plankton nets for continuous sampling such as Longhurst-Hardy type with our apparatus at the same time. We may also pay attention to advance the accuracy of measurement observing at the same region as many time as possible. In spite of the insufficiency of such method and analyses for researching distribution in the sea, we believe it must be necessary to consider the stochastical process since the homogeneity in the sea is rare.

\section{Acknowledgement}

The authors express their sincere thanks to officers and crew of R. V. Hakuho-Maru for their works.

The data analyses were carried out on a FACOM M-190 system of the computer center of Kyoto University.

\section{References}

1) A. Okuвo: J. Oceanogr. Soc. Japan., 22, 1-6 (1966).

2) R. MolinarI and A. D. KirWan Jr.: J. Phys. Ocean., 5, 483-491 (1975).

3) A. Okubo and C. C. Ebbesmeyer: Deep Sea Res. 23, 349-352 (1976)

4) A. R. Longhurst, A. D. Reith, R. E. Bower, and D. L. R. Setber'T: Deep Sea Res., 13, 213222 (1966).

5) J. H. STeELE: in "The ecology of the seas" (ed. by D. H. Cushing and J. J. WALSH), Blackwell Scientific Publications, London, 1976, pp. 98-115. 
6) M. J. R. Fashan and P. R. Pugh: Deep Sea Res., 23, 527-538 (1976).

7) K. L. Denman: Deep Sea Res., 23, 539-550 (1976).

8) T. Platt: Deep Sea Res., 19, 183-187 (1972).

9) K.S. MrLLeR: Engineering Mathematics (Translated by T. SATo and S. FUmI), Kyoritsu shuppan, Tokyo, 1960, pp. 165-170.

10) M. Morishita: Mem. Fac. Sci. Kyushu Univ. Series $E$ (Biology), 2, 215-235 (1959).

11) Y. SunAHARA: Theory of Stochastical systems (in Japanese), 1st ed., Corona-sha, Tokyo, 1979, pp. 1-71.

12) W. H. Munk and G. A. Riley: J. Mar. Res., 11, 215-240 (1952).

13) G. A. Riley, H. Stommel, and D. F. Bumpus: Bull. Bingham Oceanogr. Collection, 12, 1-169 (1949).

14) K. L. Denman and D. L. Mackas: in "Spatial pattern in plankton communities" (ed. by J. H. Steele), Plenum press, London, 1978, pp. 85-110. 